\title{
First report on Listeria monocytogenes detection in ready-to-eat chicken products in Bangladesh: $A$ glimpse into their antibiotic resistance and virulence genes.
}

\author{
Abiral Hasib Shourav \\ University of Dhaka https://orcid.org/0000-0001-8579-7909 \\ Khandokar Padmanon Salma \\ University of Dhaka \\ Sangita Ahmed ( $\nabla$ sangita@du.ac.bd) \\ University of Dhaka https://orcid.org/0000-0002-0774-4542 \\ Anisur Rahman Khan \\ University of Dhaka
}

\section{Research Article}

Keywords: Ready-to-eat meat, L. monocytogenes, virulence, antibiotic resistance, Bangladesh

Posted Date: February 28th, 2022

DOI: https://doi.org/10.21203/rs.3.rs-1402915/v1

License: (c) (i) This work is licensed under a Creative Commons Attribution 4.0 International License.

Read Full License 
4

5 Abiral Hasib Shourav ${ }^{l}$, Khandokar Padmanon Salmal, Sangita Ahmed ${ }^{1 *}$ and Md. Anisur Rahman

6 Khan $^{1}$

$7 \quad \mathbf{1}_{\text {Department of Microbiology, Faculty of Biological Sciences, University of Dhaka, Dhaka-1000. Bangladesh }}$

$8 \quad *$ Corresponding author: sangita@du.ac.bd 


\section{Abstract}

Background: Ready-to-eat (RTE) meat products are food items that are growing in popularity in Bangladesh. Albeit

11 documented with alarming prevalence of pathogenic multidrug-resistant Listeria species in these food items

12 worldwide, studies from the perspective of Bangladesh are absent. This study was devised with an aim to detect

13 pathogenic Listeria monocytogenes in some of the most popular RTE meat products in Dhaka, Bangladesh.

14 Methods: Thirty-nine such samples were investigated using biochemical tests and the Polymerase Chain Reaction

15 (PCR) analysis. The samples were RTE food products randomly collected from various departmental stores in Dhaka,

16 Bangladesh. Following confirmatory tests and detection of Listeria species, the isolates were subjected to the Kirby-

17 Bauer disc diffusion test to investigate their antibiotic-susceptibility patterns agains some of the most commonly used antibiotics to treat listeriosis - the infection caused my Listeria.

Results: Five Listeria species were detected using the biochemical and PCR tests. This constituted an overall prevalence rate of $12.8 \%(\mathrm{n}=39)$. Four out of the five Listeria species were concluded to be L. monocytogenes, while

21 the remaining one was a L. innocua isolate. PCR analysis revealed all four of the L. monocytogenes isolates to have the virulence genes $h l y A, p l c B$ and $a c t A$, although no polymorphism was detected for these genes. Despite the presence

23 of these pathogenic genes, antibiotic susceptibility tests showed promising results as some of the most commonly used

24 drugs against listeriosis were highly effective against the isolates.

25 Conclusion: Despite the fact that the isolates showed little to no antibiotic resistances against the antibiotics used in the study, the presence of three virulence genes in all four L. monocytogenes isolates is still a cause for concern. Even

27 more so, the prevalence of these pathogenic strains in a food item that is increasing in popularity in a country like outbreak occurs.

Keywords: Ready-to-eat meat, L. monocytogenes, virulence, antibiotic resistance, Bangladesh 
33 The world of science is currently aware of more than 200 diseases that may be transmitted through consuming contaminated food and food products. According to the World Health Organization (WHO), more than a million people are infected by foodborne pathogens every year (Mehlhorn, 2015). The production of food items has gone through many innovations, yet the hazards of foodborne infection have intensified over the last couple of decades. Estimates have showcased that about a quarter of the world population is at the risk of foodborne diseases and hence the death rates due to these diseases are considered a significant public health concern (Vital Signs: Listeria Illnesses, Deaths, and Outbreaks - United States, 2009-2011, n.d.).

A foodborne disease may be defined as a disorder that has been incurred due to the consumption of foodstuffs contaminated with microorganisms (i.e., bacteria, viruses, parasites and fungi, et cetera). These diseases pose major threats to public health sectors worldwide and have had adverse impacts to consumer health as well as to the economies of those countries that import them (Scallan et al., 2011). Several factors such as modifications to industrial productions, globalization of food, and new trade agreements have been implicated in the rising number of foodborne disease cases worldwide. Moreover, the demand for fresher, healthier and ready-to-eat (RTE) food with minimal or moderate production and artisanal processing has also been added to the causes of increased foodborne illness cases (Bustamante et al., 2020; Wallace et al., 2018). Ready-to-eat food products made out of meat pose a considerable health risk because they have the potential to contain harmful microorganisms. The adoption of good manufacturing practice and proper hygiene control is of paramount importance throughout the entire process of production in order to preclude food contamination by microorganisms. Temperature control is essential during the distribution of the

51 food products, or it might culminate in the growth of pathogenic organisms to levels that can cause diseases (Gil et 52 al., 2009).

Listeria monocytogenes is one of the leading bacterium notorious for the recall of RTE food from supply chains all

54 over the world (Zhu et al., 2017). Consumption of foods contaminated with L. monocytogenes gives rise to a condition 55 called listeriosis (Kumar B. N, 2016). Compared to other foodborne diseases, listeriosis is relatively rare (Borucki et 56 al., 2005). Still, because of its high fatality rate of up to 30\% (Bustamante et al., 2020), the US Food and Drug 57 Administration (FDA) adopts a zero-tolerance policy against L. monocytogenes (Borucki et al., 2005). Clinical manifestations of the condition include stillbirths, abortions, septicemia, meningitis, endocarditis, and febrile 
59 gastroenteritis. Newborn babies, elderly and immunocompromised individuals are at the highest risk of listeriosis

60 (Borucki et al., 2005; Mead et al., 1999; Shourav et al., 2020). The bacterium is Gram-positive, non-spore-forming,

61 microaerophilic, rod-shaped. It has a collection of complex physiological mechanisms that allow it a certain form of

62 ubiquity in all sorts of environmental conditions (Larsen et al., 2006). It has sevaral crucial virulence factors such as

63 hemolysin $(h l y A)$, internalin (encoded by inlA and inlB), phosphatidylinositol-specific phospholipase C (PI-PLC,

$64 p l c A)$, phosphatidylcholine-specific phospholipase C (PC-PLC, plcB) and actin polymerization protein (actA) (Jaradat

65 et al., 2002). Furhtermore, the bacterium has the ability to survive and proliferate in the gastrointestinal tract enabling

66 it to cause chronic infections (Shamloo et al., 2019).

67 The main reason Listeria monocytogenes is a significant pathogen as far as RTE food is concerned is that studies have

68 reported it to survive and proliferate at temperatures of $2 / 4{ }^{\circ} \mathrm{C}$. This aspect makes it a suitable candidate to be present

69 in foods with a long shelf-life, as RTE foods do (Todd \& Notermans, 2011; Walker et al., 1990). Ready-to-eat meat

70 products are currently items of growing popularity in Bangladesh, but studies dedicated to the prevalence of $L$.

71 monocytogenes in these foodstuffs are almost non-existent. This study was devised to investigate the scenario of $L$.

72 monocytogenes in the RTE meat products in Bangladesh and promote more public awareness against a potentially

73 fatal outbreak. 


\section{Methods}

\section{Sampling and sample processing}

77 A total of 39 samples comprising RTE meat products were collected randomly from various departmental stores in Dhaka City, Bangladesh. These samples constituted various RTE products of chicken origin such as chicken sausage, chicken salami, chicken loaf and chicken sandwich meat.

80

81

Processing of the samples was carried out according to the procedures followed by a previous study (Shourav et al., 2020). Twenty-five grams of each sample was weighed, homogenized in a pre-sterilized homogenizer and mixed with $225 \mathrm{ml}$ Listeria Enrichment Broth (Oxoid Ltd., Hampshire, UK). The mixture was shaken thoroughly to make it homogenous before incubation at $30^{\circ} \mathrm{C}$ for $48 \mathrm{~h}$. Prior to inoculation, the Listeria Enrichment Media was mixed with Listeria Selective Enrichment Supplement (Oxoid Ltd., Hampshire, UK) as per the manufacturer's instructions in an effort to prevent the growth of any other organism except Listeria spp. (SR0141, Listeria Selective Enrichment Supplement $\mid$ Oxoid - Product Detail, n.d.).

\section{Isolation of Listeria spp.}

Polymyxin Acriflavin Lithium-chloride Ceftazidime Esculin Mannitol (PALCAM) Agar (Oxoid Ltd., Hampshire, UK) medium was used for the selective isolation of Listeria spp. Following enrichment, a loop-full of the culture was streaked on PALCAM agar plate and incubated at $37^{\circ} \mathrm{C}$ for $24-48 \mathrm{~h}$. On PALCAM agar plates, Listeria spp. colonies manifested as black or black-green color with a black halo and a sunken center having a growth diameter of 1-2 mm (Scotter et al., 2001). Five suspected Listeria spp. colonies were carefully selected from a plate and each was inoculated into Tryptose Soya Broth Yeast Extract (TSBYE, Oxoid Ltd., Hampshire, UK) and incubated at $37^{\circ} \mathrm{C}$ for 1 hour. After that, the suspension was inoculated into Tryptone Soya Yeast Extract Agar (TSYEA, Himeadia, India) and incubated at $37^{\circ} \mathrm{C}$ for $24 \mathrm{~h}$. The colonies that grew on the TSYEA media were presumptively pure Listeria spp. The aforementioned several steps of isolation ensured a greater extent of precision to the isolation of the Listeria spp. (Gebretsadik et al., 2011).

\section{Phenotypic identification of potential Listeria spp. isolates}

Morphological characteristics of the isolates were examined using the Gram staining technique. Typical Listeria spp. isolates surfaced as Gram-positive short rods under a light microscope. These isolates were then screened further by 
means of a collection of confirmative biochemical tests that included catalase, oxidase, urease, acid formation, gas production and hydrogen sulfide production (Kligler's Iron Agar), indole formation, motility, methyl red and VogesProskauer (MR-VP) tests. Listeria monocytogenes ATCC 19117 (Listeria Monocytogenes (Murray et Al.) Pirie ATCC ( $19117^{T M}$, n.d.) was used as a reference strain (positive control) so as to compare with the results of the isolates under study.

\section{PCR based identification and virulence gene detection in the Listeria spp. isolates}

The presumptive Listeria spp. isolates were subjected to the Polymerase Chain Reaction (PCR) based amplification of the $16 \mathrm{~S} r R N A$ gene followed by sequencing. An attempt was also made to detect the virulence-associated genes $h l y A$, actA and $p l c B$. For every the PCR reactions, the final reaction volume was $25 \mu 1$ containing $12.5 \mu 1$ Mastermix (DreamTaq Green PCR Mastermix, Thermo Fisher Scientific, USA), $0.5 \mu 1$ forward primer, $0.5 \mu 1$ reverse primer, 2.0 $\mu l$ genomic DNA as template and sterile nuclease-free water to make up the volume.

\section{Amplification of 16S rRNA gene and sequencing}

114 Whole genomic DNA was extracted by boiling method from each of the isolates deemed as Listeria by the colony morphology and biochemical tests (Bai et al., 2010). Concentrations of the genomic DNA were measured using a NanoDrop ${ }^{\mathrm{TM}} 8000$ spectrophotometer (Thermo Scientific, California, USA). The 16S rRNA gene was amplified in a

117 thermal cycler (Applied Biosystems ${ }^{\circledR}$ Veriti ${ }^{\circledR}$ 96-Well Thermal Cycler) using primer pairs shown in Table 1. The 118 reaction conditions included initial denaturation at $94^{\circ} \mathrm{C}$ for 5 minutes, 30 cycles of amplification at $94^{\circ} \mathrm{C}$ for 1 minutes and 30 seconds, annealing at $55^{\circ} \mathrm{C}$ for 1 minute and finally extension at $72^{\circ} \mathrm{C}$ for 1 minutes and 30 seconds. The PCR

120 products were separated and visualized on agarose gel (1-2\%) following ethidium bromide staining. With strict 121 adherence to the manufacturers' instructions, a PCR cleaning kit (Favorgen, Taiwan) was used to clean the amplified products and about $0.5-1.00 \mu \mathrm{g}$ of the purified product was sent to Macrogen (Korea) for sequencing. The forward

123 and reverse primers generated partial sequences that were cleaned manually and combined to obtain a full-length 124 sequence (about $1000 \mathrm{bp}$ ) using the Seqman Genome Assembler (DNAstar, USA). Full-length sequences were 125 compared with sequences in the GenBank database of the National Center for Biotechnology Information (NCBI) 126 (http://www.ncbi.nlm.nih.gov/GenBank) using the Basic Local Alignment Search Tool (BLAST) to identify close 127 phylogenetic relatives. The $16 S r R N A$ gene sequences and their respective reference sequences from NCBI were 128 aligned using ClustalW program, available in MEGA-X (Kumar et al., 2018), and a phylogenetic tree was constructed 
129 using the neighbor-joining analysis in the MEGA X software (Saitou \& Nei, 1987). The full length $16 S$ rRNA gene 130 sequences were submitted to the NCBI GenBank nucleotide sequence database. The isolates were designated with

131 accession numbers by NCBI GenBank after necessary verifications (Table 2).

\section{Molecular detection of virulence-associated gene}

133 The PCR conditions for the amplification of the virulence-associated genes $h l y A, a c t A$ and $p l c B$ are as follows:

134 denaturation of DNA template at $94^{\circ} \mathrm{C}$ for $3 \mathrm{~min}$, followed by 35 cycles of amplification (each cycle comprised of 135 denaturation at $94^{\circ} \mathrm{C}$ for $1 \mathrm{~min}$, annealing at $60{ }^{\circ} \mathrm{C}$ for $2 \mathrm{~min}$ and extension at $72{ }^{\circ} \mathrm{C}$ for $1 \mathrm{~min}$ ) in a Thermal Cycler 136 (Applied Biosystems ${ }^{\circledR}$ Veriti ${ }^{\circledR}$ 96-Well Thermal Cycler ). Agarose gel electrophoresis (1-2\%) and staining by 137 ethidium bromide was used to visualize the PCR products (Jaradat et al., 2002). Primer pairs used are indicated in 138 Table 1. Listeria monocytogenes ATCC 19117 was used as a positive control while a lab owned random strain of 139 Escherichia coli was used as negative control.

140 Table 1 Primer pairs used for the PCR-based amplifications of assorted genes in the isolated Listeria spp.

\begin{tabular}{|c|c|c|c|c|}
\hline $\begin{array}{l}\text { Targeted } \\
\text { gene }\end{array}$ & & Primer sequences (5`-3’) & $\begin{array}{l}\text { Product } \\
\text { size (bp) }\end{array}$ & Reference \\
\hline $16 S r R N A$ & $27 \mathrm{~F}$ & AGA GTT TGG ATC M TGG CTC AG & & \\
\hline \multirow[t]{2}{*}{ gene } & 907R & CCG TCA ATT CCT TTR AGT TT & 1000 & (Jiang et al., 2006) \\
\hline & $\mathbf{F}$ & CGG AGG TTC CGC AAA AGA TG & & \\
\hline \multirow[t]{3}{*}{ hlyA } & $\mathbf{R}$ & CCT CCA GAG TGA TCG ATG TT & 234 & (Jaradat et al., \\
\hline & & & & 2002) \\
\hline & $\mathbf{F}$ & GAC GAA AAT CCC GAA GTG AA & & \\
\hline \multirow[t]{3}{*}{ actA } & $\mathbf{R}$ & CTA GCG AAG GTG CTG TTT CC & 268 & (Jaradat et al., \\
\hline & & & & 2002) \\
\hline & $\mathbf{F}$ & GGG AAA TTT GAC ACA GCG TT & & \\
\hline \multirow[t]{2}{*}{$p l c B$} & $\mathbf{R}$ & ATT TTC GGG TAG TCC GCT TT & 261 & (Jaradat et al., \\
\hline & & & & 2002) \\
\hline
\end{tabular}

141 
143 The isolates were tested for antimicrobial susceptibility using the Kirby-Bauer Disc diffusion method (Hudzicki, 144 2012). Each Listeria isolate was grown in an LB broth until the log phase was reached and its turbidity was adjusted 145 to $0.5 \mathrm{McFarland}$ standard $\left(O D_{625 \mathrm{~nm}}=0.08-0.13\right)$ spectrophotometrically. Freshly prepared standardized cultures 146 of each isolate were spread on Mueller-Hinton (MH) agar plates using sterile cotton swabs and allowed to stand for 147 3-5 minutes inside the biosafety cabinet. No more than four antibiotic discs, approximately $40 \mathrm{~mm}$ apart from each 148 other, were positioned on a single $\mathrm{MH}$ agar plate and incubated at $37^{\circ} \mathrm{C}$ for $16 \mathrm{~h}$. The diameter of the clear zone around 149 each antibiotic disc was measured. The data was used to work out the level of susceptibility of the isolates to a particular antibiotic (Hudzicki, 2012). The isolates were classified as sensitive (S), intermediate (I), and resistant (R)

151 based on the diffusion zone breakpoints described by Clinical and Laboratory Standards Institute (CLSI) guidelines for Staphylococcus aureus ATCC 25923 and Escherichia coli ATCC 25922 (Issa et al., 2011; Olaniran et al., 2015; Shourav et al., 2020). Multiple Antibiotic Resistance (MAR) index was calculated as follows: $M A R=a / b$, where $a=$ number of antibiotics to which the isolate was resistant; $b=$ total number of antibiotics against which individual isolate was tested.

\section{Results}

\section{Isolation of presumptive Listeria spp. isolates}

Based on the growth pattern on PALCAM agar media (Figure 1), a total of 17 isolates $(43.6, n=39)$ were selected from plates belonging to the 39 RTE meat product samples. The colonies surfaced as black or black-green color with a black halo and a sunken center with a 1-2 mm (Scotter et al., 2001). No discernible Listeria-like growth pattern was observed in the plates corresponding to the raw chicken meat samples.

\section{Identification of Listeria spp. isolates}

The Gram reaction was used to confirm the morphology of the presumptive Listeria spp. isolates. Under a light microscope at 100X magnification, the isolates were visualized as Gram-positive short rods. Following Gram reaction and Biochemical tests, 10 isolates $(25.6 \%, \mathrm{n}=39)$ showed results typical of Listeria spp. In the assorted biochemical tests (Table 2), the isolates presumed as Listeria spp. showed catalase positive, oxidase negative, urease negative, positive acid formation, negative gas formation, negative hydrogen sulfide formation, negative indole production, 
positive motility and positive MR-VP tests. Listeria monocytogenes ATCC 19117 was used as a reference strain to confirm the genus level identification of isolates as Listeria.

Table 2 Biochemical tests result of the suspected Listeria spp. isolates

\begin{tabular}{|c|c|c|c|c|c|c|c|c|c|c|c|}
\hline \multirow[b]{3}{*}{ Isolates } & \multicolumn{11}{|c|}{ Biochemical Tests } \\
\hline & \multirow{2}{*}{ 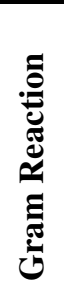 } & \multirow{2}{*}{ 总 } & \multirow{2}{*}{ 苞 } & Kligl & (KIA) & Agar & \multirow{2}{*}{ 厗 } & \multirow{2}{*}{$\frac{0}{\frac{\pi}{g}}$} & \multirow{2}{*}{ 总 } & \multirow{2}{*}{ 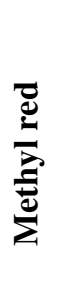 } & \multirow{2}{*}{ 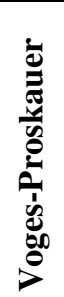 } \\
\hline & & & & Acid & Gas & $\mathrm{H}_{2} \mathrm{~S}$ & & & & & \\
\hline$\overline{\text { PSABD1 }}$ & + & + & - & + & - & - & + & - & - & + & + \\
\hline PSABD4 & + & + & - & + & - & - & - & - & - & + & + \\
\hline PSABD7 & + & + & - & + & - & - & + & - & - & + & + \\
\hline PSABD11 & + & + & - & + & - & - & + & - & - & + & + \\
\hline PSABD16 & + & + & - & + & - & - & + & - & - & + & + \\
\hline $\begin{array}{l}\text { Positive control } \\
\text { (L. monocytogenes }\end{array}$ & + & + & - & + & - & - & + & - & - & + & + \\
\hline ATCC 19117) & & & & & & & & & & & \\
\hline
\end{tabular}

171

Molecular confirmation of potential Listeria spp. isolates by $16 \mathrm{~S}$ rRNA gene sequencing

173 Based on the homology search of the 16S rRNA gene sequences using BLAST, 5 isolates showed $98-99 \%$ similarity 174 with Listeria spp. sequences from NCBI GenBank. Table 3 depicts the accession number of the partial $16 S$ rRNA gene 175 sequences designated by GenBank to the isolates of this study. Apart from the isolate PSABD4, the other isolates of 176 the study showed high similarity $(98-99 \%)$ with Listeria monocytogenes sequences available in GenBank. Only 177 isolate PSABD4 was similar to a Listeria innocua sequence.

178 The partial $16 S$ rRNA gene sequences of the isolates in this study along with the reference sequences from GenBank 179 were used to construct a phylogenetic tree (Figure 1). The evolutionary history was inferred using the Neighbor180 Joining method (Saitou \& Nei, 1987). The optimal tree with the sum of branch length $=0.59974477$ is shown. The 
181 percentage of replicate trees in which the associated taxa clustered together in the bootstrap test (1000 replicates) are

182 shown next to the branches (Felsenstein, 1985). The tree is drawn to scale, with branch lengths in the same units as

183 those of the evolutionary distances used to infer the phylogenetic tree. The evolutionary distances were computed

184 using the Kimura 2-parameter method (Kimura, 1980) and are in the units of the number of base substitutions per site.

185 This analysis involved 11 nucleotide sequences. All positions containing gaps and missing data were eliminated

186 (complete deletion option). There was a total of 759 positions in the final dataset. Evolutionary analyses were

187 conducted in MEGA X (Kumar et al., 2018). Halobacterium volcanii (Accession number: K0042.1) served as an

188 outgroup for the tree.

189 Table 3 Identification of strains based on 16S rRNA gene sequencing and their accession numbers published in 190 DNA data base

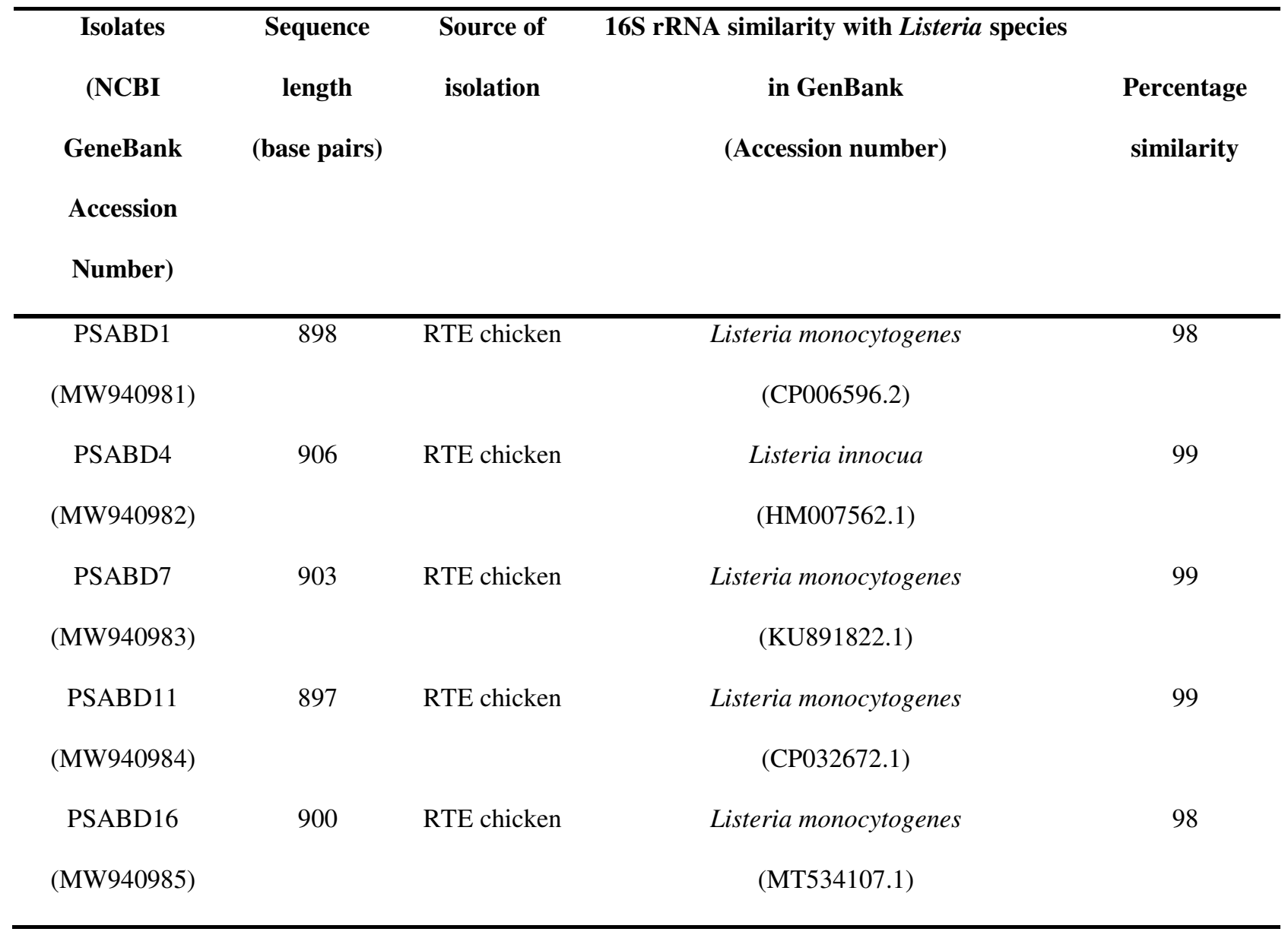

191 


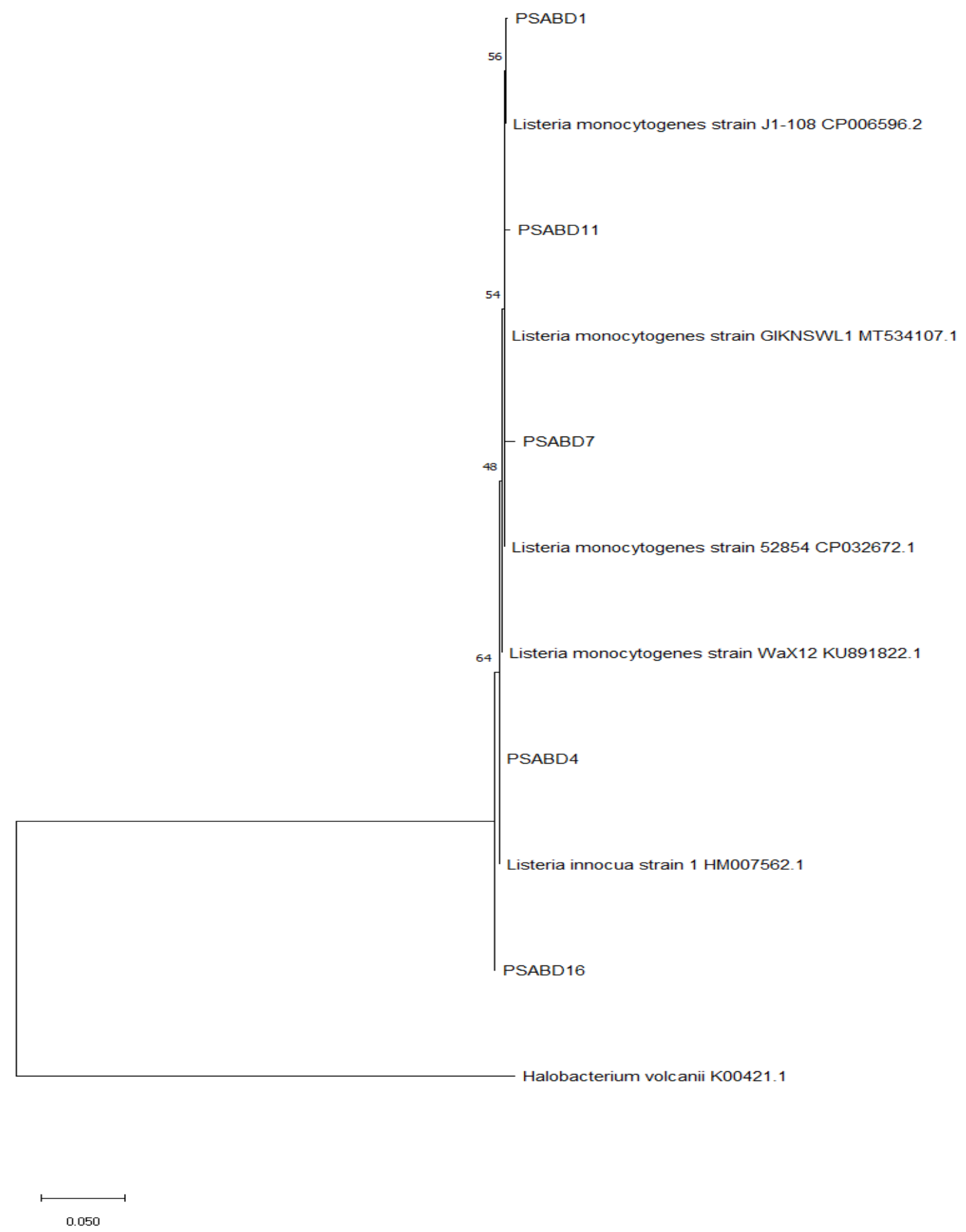

Fig. 1 Phylogenetic analysis of partial 16S rRNA gene sequences and related species by neighbor-joining method 192 


\section{Detection of virulence-associated genes}

194 The four suspected L. monocytogenes isolates (i.e. PSABD1, PSABD7, PSABD11, PSABD16) were subjected to PCR

195 with a view to amplify three virulence-associated genes ( $h l y A$, actA and plcB). Following analysis, all 4 isolates

196 depicted the presence of $h l y A, a c t A$ and $p l c B$ (Fig. 2). However, none of the genes showed any polymorphism.

A: $h l y A$

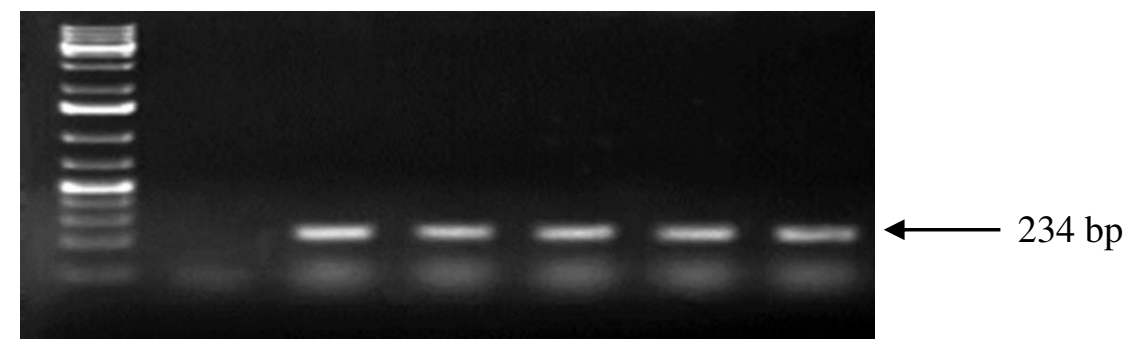

$\begin{array}{lllllll}\mathrm{L} & 1 & 2 & 3 & 4 & 5 & 6\end{array}$

B: $a c t A$
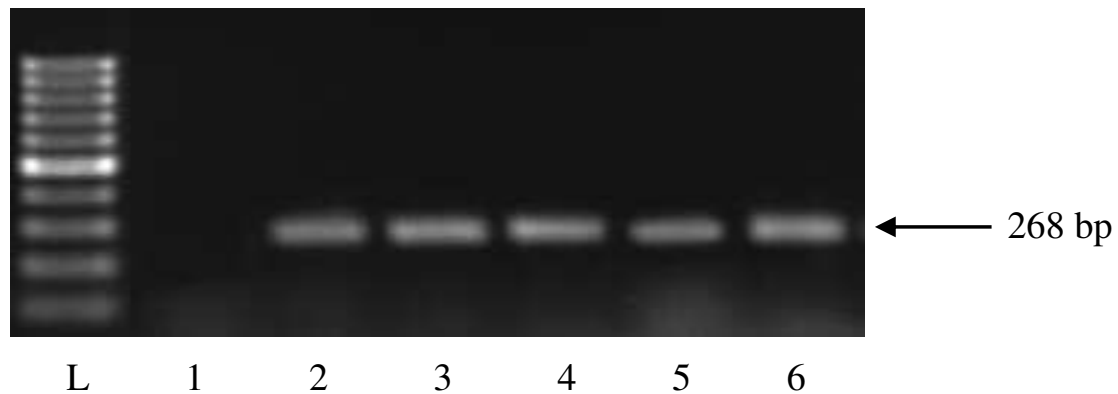

C: $p l c B$

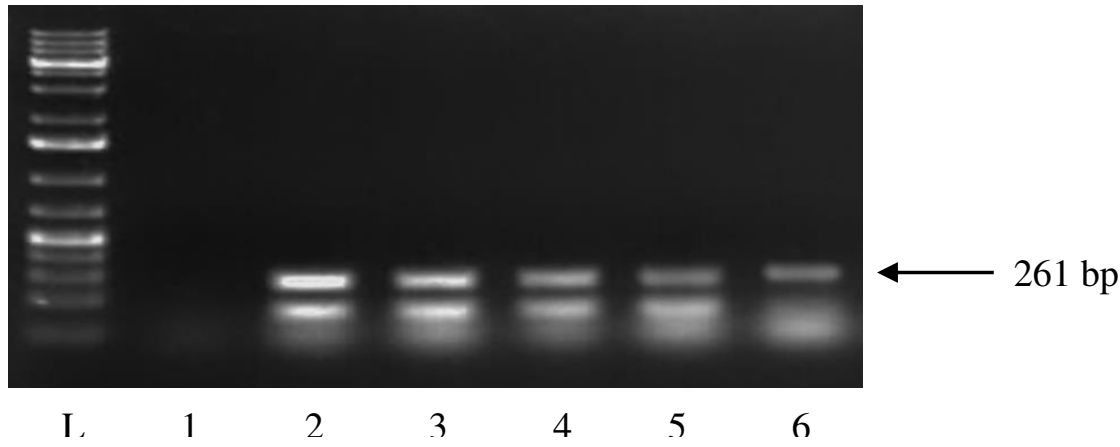

Fig. 2 PCR amplification of the genes hlyA (picture A), actA (picture B) and plcB (Picture C). In all three gel pictures, lane $\mathrm{L}$ represents $1 \mathrm{~kb}+\mathrm{DNA}$ ladder, and lanes 1 through 6 represent the negative control, the positive control (L. monocytogenes ATCC 19117) and the isolates PSABD1, PSABD7, PSABD11 and PSABD16 respectively. 
203 The results of antibiotic susceptibility test of the Listeria spp. isolates against a panel of eight antibiotics were

204 tabulated in Table 4. The highest resistance, at 40\%, was shown against both erythromycin and rifampicin.

205 Complete susceptibility was depicted by all 5 Listeria spp. isolates of the study against streptomycin,

206 sulfamethoxazole-trimethoprim, tetracycline and chloramphenicol. After these antibiotics, ampicillin showed the

207 second-highest efficiency as $80 \%$ of the isolates were susceptible to it.

208 Table 4 Antibiotic susceptibility profile of the Listeria spp. isolates

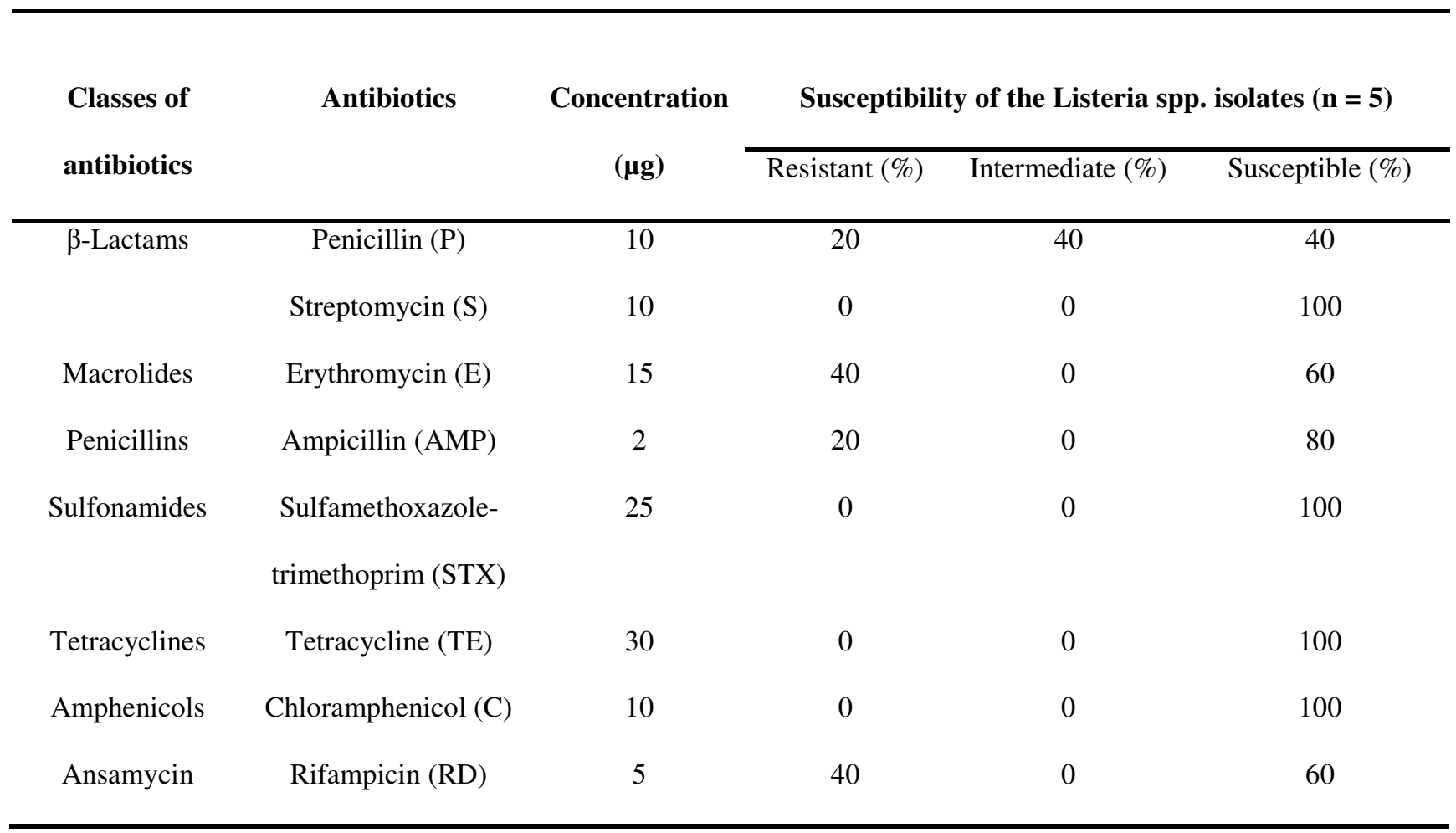

210 Data generated by the antibiotic susceptibility test was used to calculate the Multiple Antibiotic Resistance (MAR)

211 indices for the isolates (Figure 3). Isolates PSABD 11 and PSABD 16 scored 0 MAR indices which means that these

212 isolates were susceptible to all the antibiotics used on them. PSABD7 showed resistance against only 3 of the 8

213 antibiotics tested, giving it a MAR index score of 0.375. Likewise, PSABD4 and PSABD1 were resistant against 2

214 and 1 antibiotics respectively. 


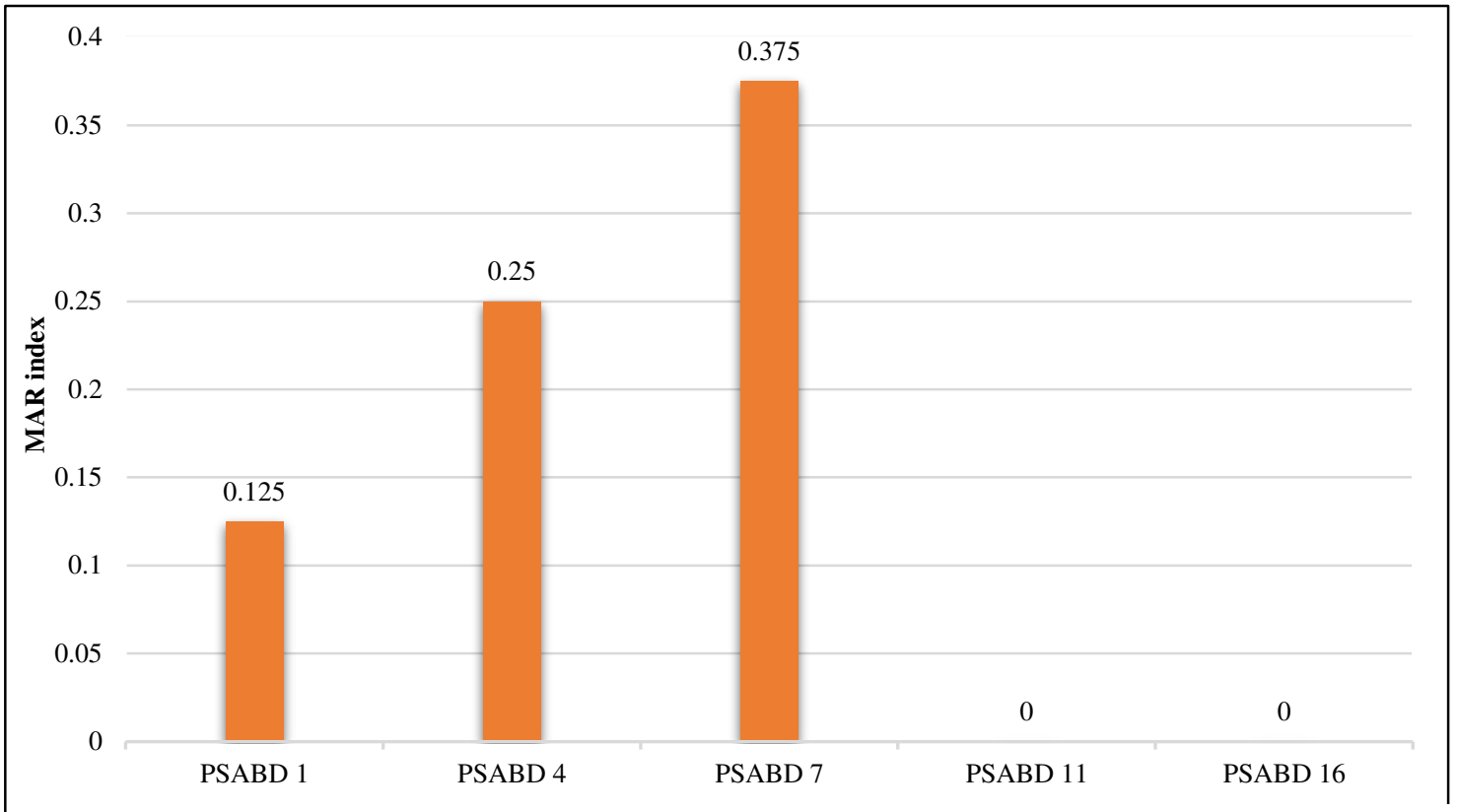

Fig. 3 Multiple Antibiotic Resistance (MAR) index of the Listeria spp. isolate 
The remarkable ability of Listeria monocytogenes to persist in the harshest of conditions for great lengths of time has allowed it to easily breakthrough into food chains (Carpentier \& Cerf, 2011). This has caused relevant authorities from several developed countries to implement strict guidelines against $L$. monocytogenes over the decades (Prevention, 2013). On the other hand, the epidemiological knowledge on listeriosis in developing countries is largely underappreciated as regulations against L. monocytogenes in these countries are almost non-existent. In Bangladesh, for instance, incidence rate of listeriosis is unknown and several factors can be attributed to it: lack of public awareness, overwhelmed medical sectors with other common diseases and underreporting of cases (Islam et al., 2016). Previously, there have been a few studies in Bangladesh addressing the incidence of Listeria in dairy food products and environment (Manjur et al., 2018), cattle farm environment (Shourav et al., 2020) and raw beef, chicken and chevon (Islam et al., 2016). To the best of our knowledge, this is the first study investigating the prevalence of multi-drug resistant pathogenic L. monocytogenes in RTE meat products in Bangladesh.

The present study analyzed 39 samples of RTE chicken meat products for the presence of $L$. monocytogenes. By means of Listeria-specific biochemical and molecular detection methods, 5 Listeria spp. isolates were detected and characterized. Out of these, 4 isolates were confirmed to be L. monocytogenes (Fig. 2). This made the overall prevalence rate of Listeria spp. $12.8 \%(\mathrm{n}=39)$ and the prevalence rate of L. monocytogenes $10.3 \%(\mathrm{n}=39)$. The overall prevalence of $12.8 \%$ conforms with studies by Uyttendaele et al. (Uyttendaele et al., 1999) and Islam et al. (Islam et al., 2016). The RTE food products investigated in this study are all sold as frozen food in Bangladesh, having a high shelf life. Although the other typical foodborne pathogens in the country may not find this environment as

237 be a reason for the documented prevalence in this study.

238 Previous investigations into the virulence factors of L. monocytogenes have observed that about $8 \%$ to $21 \%$ of the 239 isolates can be either weakly virulent or completely avirulent (Bustamante et al., 2020). The detection of hlyA, actA and plcB genes (Fig. 2) in all four of the L. monocytogenes in our research suggests that the isolates have the potential

241 to be pathogenic. However, the genes detected did not show any polymorphism even though the manifestation this

242 phenomenon has been documented in these genes previously. Previous researches have demonstrated actA gene to 243 be polymorphic and that L. monocytogenes can be classified into two different categories based on polymorphism in actA (Wiedmann et al., 1997). Polymorphism has also been demonstrated for hlyA gene by another study (Vines \& 
Swaminathan, 1998). The absence of polymorphism in the genes detected in our study could be due to a few reasons: the target regions for the primer pairs used could have been too small for any variation to be detected or the target sequences might have been located outside the regions of polymorphism. The accurate picture of polymorphism in these genes could be revealed by sequence analysis.

By the last few decades, there has been a rising number of cases of antibiotic resistance in Listeria spp. since it was first detected in 1990 (Poyart-Salmeron et al., 1990). Despite that, treatment of listeriosis still involves the use of antibiotics and Listeria spp. are susceptible to those antibiotics that are generally aimed against Gram-positive bacteria (e.g. ampicillin, penicillin G, tetracyclines, amoxicillin, chloramphenicol et cetera) (Bustamante et al., 2020). The AMR studies in our research revealed that the pattern of resistance in the isolates was not so high. Isolates PSABD11 and PSABD16 registered 0 scores of MAR, as shown in Fig. 3. This means that these two isolates had no resistance whatsoever against the antibiotics tested on them. Isolate PSABD7 demonstrated the highest resistance with a MAR index of only 0.375 , followed by PSABD4 and PSABD1 with MAR indices of 0.25 and 0.125 . Moreover, all the isolates were completely susceptible (Table 4) to streptomycin, sulfamethoxazole-trimethoprim, tetracycline and chloramphenicol. The sensitivity pattern to sulfamethoxazole-trimethoprim is promising because it is used to treat listeriosis patients who are allergic to penicillin (Bajkó et al., 2013) and penicillin, being the gold standard of listeriosis treatment (Martínez-Martínez et al., 2001), was effective against only 40\% of the isolates in the study. Ampicillin, one of the primary drugs of choice for the treatment of listeriosis (Shourav et al., 2020), was effective against $80 \%$ of the isolates. This is particularly significant because two previous studies on Listeria conducted in Bangladesh (Islam et al., 2016; Shourav et al., 2020) found contrasting resistance patterns against ampicillin in their respective isolates.

264 Results demonstrated by the AMR pattern of the isolates in our study was not as alarming as other studies have 265 reported in the past, but the detection of virulence-associated hlyA, actA and plcB genes in all 4 of the $L$. monocytogenes isolates could be a cause for concern, especially when the foodstuffs investigated are growing in popularity. Due to financial constraints, our study was limited to examining a relatively small number of samples but the prevalence rates calculated are in close agreement with several published reports worldwide. Although the results of this study cannot be extrapolated to a larger number of samples, it still provides an insight into the risks associated with RTE chicken meat products in Bangladesh. Hence, food and health authorities in the country need to enforce 271 more active control and surveillance of these food items. 


\section{CONCLUSION}

273 Being a developing country, Bangladesh has a public health sector that stays overwhelmed with various foodborne

274 diseases throughout the year. With hardly any prior scientific research conducted on Listeria spp. from the country's

275 context, an outbreak of listeriosis could have a catastrophic effect on the population. Our study has demonstrated that

276 pathogenic strains of L. monocytogenes are prevalent in RTE meat products commercially available in the country.

277 As public popularity towards these food items increases, it is crucial that the government-run health and food

278 authorities take a closer look at the quality control of these food products and enforce relevant regulations on their

279 manufacturing process just as the developed countries of the world do.

\section{Abbreviations}

281 RTE: Ready-to-Eat; PCR: Polymerase Chain Reaction; PALCAM: Polymyxin Acriflavin Lithium-chloride

282 Ceftazidime Esculin Mannitol; hlyA: hemolysin A; actA: actin-polymerizing protein A; plcB: phospholipase B

\section{Acknowledgments}

284 The authors acknowledge Professor Dr Mahmuda Yasmin and Professor Dr Anowara Begum from Department of 285 Microbiology, University of Dhaka for providing technical support to conduct the research.

\section{Authors' Contributions}

287 Mr Abiral Hasib Shourav analysed the data, prepared the original draft. Ms Khandoker Padmanon Salma took part in 288 the investigation, formal analysis of data while Professor Dr Sangita Ahmed conceptualized the research work and 289 was involved in developing methodology, acquisition of fund, supervision of research work and editing of the 290 manuscript. Md. Anisur Rahman Khan supervised the research work and manuscript preparation.

\section{Funding}

292 This work was funded by Bangladesh Ministry of Science and Technology, Government of the People's Republic of 293 Bangladesh and Biotechnology Research Center, University of Dhaka.

294 Availability of Data and Materials

295 The datasets generated during and/or analyzed during the current study are available from the corresponding author 296 on reasonable request. 
297 Ethics approval and consent to participate

$298 \quad$ Not applicable

299 Consent for publication

$300 \quad$ Not applicable

301 Competing interests

302 The authors declare that they have no competing interests 


\section{References}

304

305

306

307

308

309

310

Bai J, Shi X, Nagaraja T. G (2010) A multiplex PCR procedure for the detection of six major virulence genes in Escherichia coli O157:H7. Journal of Microbiological Methods 82:85-89. https://doi.org/10.1016/j.mimet.2010.05.003

Bajkó Z, Bălaşa R, Maier S, Moțăţăianu A, Treabă A, Macarie I, Gârbovan C, Chiriac C (2013) Listeria monocytogenes meningoencephalitis mimicking stroke in a patient with chronic lymphocytic leukemia. Neurology and Therapy 2:63-70. https://doi.org/10.1007/s40120-013-0009-y

Borucki MK, Gay CC, Reynolds J, McElwain KL, Kim SH, Call DR, Knowles DP (2005) Genetic diversity of Listeria monocytogenes strains from a high-prevalence dairy farm. Applied and Environmental Microbiology 71:5893-5899. https://doi.org/10.1128/AEM.71.10.5893-5899.2005

Bustamante F, Maury-Sintjago E, Cerda Leal F, Acuña S, Aguirre J, Troncoso M, Figueroa G, Parra-Flores J (2020) Presence of listeria monocytogenes in ready-to-eat artisanal chilean foods. Microorganisms 8:1-18. https://doi.org/10.3390/microorganisms8111669

Carpentier B, Cerf O (2011) Persistence of Listeria monocytogenes in food industry equipment and premises. International Journal of Food Microbiology 145:1-8. https://doi.org/ 10.1016/j.ijfoodmicro.2011.01.005

Felsenstein J (1985) Confidence limits on phylogenies: an approach using the bootstrap. Evolution 39:783-791. https://doi.org/10.1111/j.1558-5646.1985.tb00420.x

Gebretsadik S, Kassa T, Alemayehu H, Huruy K, Kebede N (2011) Isolation and characterization of Listeria monocytogenes and other Listeria species in foods of animal origin in Addis Ababa, Ethiopia. Journal of Infection and Public Health 4:22-29. https://doi.org/10.1016/j.jiph.2010.10.002

Gil M I, Allende A, López Gálvez F, Selma MV (2009) Hay alternativas al cloro como higienizante para productos de IV Gama. Revista Horticultura. Mayo. http://www.horticom.com/revistasonline/extras/extra09/38_45.pdf. Accessed 3 May 2021

Hudzicki J (2012) Kirby-Bauer Disk Diffusion Susceptibility Test Protocol Author Information. American Society For Microbiology, December 2009, 1-13. https://www.asm.org/Protocols/Kirby-Bauer-Disk-Diffusion- 
Islam MS, Husna AA, Islam MA, Khatun M M (2016) Prevalence of Listeria monocytogenes in Beef, Chevon and Chicken in Bangladesh. American Journal of Food Science and Health 2:39-44. http://www.aiscience.org/journal/ajfshhttp://creativecommons.org/licenses/by/4.0/

Issa ZM, Yen LH, Radu S (2011) Antibiogram Profiles of Listeria monocytogenes isolated from foods. 2011 2nd International Conference on Biotechnology and Food Science 7:133-137. http://www.ipcbee.com/vol7/31ICBFS2011S10043.pdf. Accessed 10 May, 2021

Jaradat ZW, Schutze GE, Bhunia AK (2002) Genetic homogeneity among Listeria monocytogenes strains from

Jiang H, Dong H, Zhang G, Yu B, Chapman LR, Fields MW (2006) Microbial diversity in water and sediment of

Kumar S, Stecher G, Li M, Knyaz C, Tamura K (2018) MEGA X: molecular evolutionary genetics analysis across

PCR analysis of virulence genes. International Journal of Food Microbiology 76:1-10.

https://doi.org/10.1016/S0168-1605(02)00050-8

Kimura M (1980) A simple method for estimating evolutionary rates of base substitutions through comparative studies of nucleotide sequences. Journal of Molecular Evolution 16:111-120.

https://doi.org/10.1007/BF01731581

Kumar BNV (2016) Molecular characterization and antibiogram of Listeria monocytogenes isolated from chicken and mutton of retail markets. Journal of Microbiology and Infectious Diseases 6:65-68. https://doi.org/10.5799/ahinjs.02.2016.02.0218 computing platforms. Molecular Biology and Evolution 35:1547-1549. https://doi.org/10.1093/molbev/msy096

Kumar S, Stecher G, Tamura K (2016) MEGA7: Molecular Evolutionary Genetics Analysis Version 7.0 for Bigger 
Larsen, MH, Kallipolitis BH, Christiansen JK, Olsen JE, Ingmer H (2006) The response regulator ResD modulates virulence gene expression in response to carbohydrates in Listeria monocytogenes. Molecular Microbiology, 61:1622-1635. https://doi.org/10.1111/j.1365-2958.2006.05328.x

Listeria monocytogenes (Murray et al.) Pirie ATCC ® $19117^{T M}$. (n.d.). https://www.atcc.org/products/all/19117.aspx\#generalinformation. Accessed April 29, 2020

Manjur MSE, Siddique S, Ahmed S (2018) Multi-drug resistant pathogenic Listeria monocytogenes in surface water and soil samples of Dhaka city. Bangladesh Journal of Microbiology 33:39-42. https://doi.org/10.3329/bjm.v33i1.39602

Martínez-Martínez L, Joyanes P, Suárez AI, Perea EJ (2001) Activities of gemifloxacin and five other antimicrobial

Mehlhorn, H (2015) Food-Borne Disease Burden Epidemiology Reference Group. Encyclopedia of Parasitology, 1agents against Listeria monocytogenes and coryneform bacteria isolated from clinical samples. Antimicrobial Agents and Chemotherapy 45:2390-2392. https://doi.org/10.1128/AAC.45.8.2390-2392.2001

Mead PS, Slutsker L, Dietz V, McCaig LF, Bresee JS, Shapiro C, Griffin PM, Tauxe RV (1999) Food-related illness and death in the United States. Emerging Infectious Diseases 5:607-625. https://doi.org/10.3201/eid0505.990502 1. https://doi.org/10.1007/978-3-642-27769-6_3884-1

Olaniran AO, Nzimande SBT, Mkize NG (2015) Antimicrobial resistance and virulence signatures of Listeria and Aeromonas species recovered from treated wastewater effluent and receiving surface water in Durban, South Africa. BMC Microbiology 15:1-10. https://doi.org/10.1186/s12866-015-0570-x

Poyart-Salmeron C, Carlier C, Trieu-Cuot P, Courtieu AL, Courvalin P (1990) Transferable plasmid-mediated antibiotic resistance in Listeria monocytogenes. Lancet (London, England) 335:1422-1426. https://doi.org/10.1016/0140-6736(90)91447-i

Prevention, C. for D. C. and. (2013). CDC.(2013) Multistate outbreak of listeriosis linked to whole cantaloupes from Jensen Farms, Colorado. https://www.cdc.gov/listeria/outbreaks/cantaloupes-jensen-farms/index.html. 
Accessed 5 May 2021

Saitou N, Nei M (1987) The neighbor-joining method: a new method for reconstructing phylogenetic trees. Molecular Biology and Evolution 4:406-425. https://doi.org/10.1093/oxfordjournals.molbev.a040454

Scallan E, Hoekstra RM, Angulo FJ, Tauxe RV, Widdowson MA, Roy SL, Jones, J L, Griffin PM (2011) Foodborne illness acquired in the United States-Major pathogens. Emerging Infectious Diseases 17:7-15. https://doi.org/10.3201/eid1701.P11101

Scotter SL, Langton S, Lombard B, Schulten S, Nagelkerke N, In't Veld PH, Rollier P, Lahellec C (2001) Validation of ISO method 11290 part 1--detection of Listeria monocytogenes in foods. International Journal of Food Microbiology 64:295-306. https://doi.org/10.1016/s0168-1605(00)00462-1

Shamloo E, Hosseini H, Moghadam AZ, Larsen HM, Haslberger A, Alebouyeh M (2019) Importance of Listeria monocytogenes in food safety: A review of its prevalence, detection, and antibiotic resistance. In Iranian Journal of Veterinary Research 20:241-254. https://www.ncbi.nlm.nih.gov/pmc/articles/PMC6983307/

Shourav AH, Hasan M, Ahmed S (2020) Antibiotic susceptibility pattern of Listeria spp. isolated from cattle farm environment in Bangladesh. Journal of Agriculture and Food Research 2:100082. https://doi.org/10.1016/j.jafr.2020.100082

SR0141, Listeria Selective Enrichment Supplement | Oxoid - Product Detail. (n.d.). http://www.oxoid.com/UK/blue/prod_detail/prod_detail.asp?pr=SR0141\&cat=\&c=UK\&lang=EN. Accessed August 21, 2020

Todd ECD, Notermans S (2011) Surveillance of listeriosis and its causative pathogen, Listeria monocytogenes. Food Control 22:1484-1490. https://doi.org/10.1016/j.foodcont.2010.07.021

Uyttendaele M, De Troy P, Debevere J (1999) Incidence of Listeria monocytogenes in different types of meat products on the Belgian retail market. International Journal of Food Microbiology 53:75-80. https://doi.org/10.1016/S0168-1605(99)00155-5

Vines A, and Swaminathan B (1998) Identification and characterization of nucleotide sequence differences in three 
virulence-associated genes of Listeria monocytogenes strains representing clinically important serotypes.

405 Vital Signs: Listeria Illnesses, Deaths, and Outbreaks - United States, 2009-2011. (n.d.).

406 https://www.cdc.gov/mmwr/preview/mmwrhtml/mm6222a4.htm. Accessed April 29, 2021

407 Walker SJ, Archer P, Banks JG (1990) Growth of Listeria monocytogenes at refrigeration temperatures. Journal of Applied Bacteriology 68:157-162. https://doi.org/ 10.1111/j.1365-2672.1990.tb02561.x

409 Wallace C., Sperber W., Mortimore S. Food Safety for the 21st Century, Managing HACCP and Food Safety Throughout the Global Supply Chain. 2nd ed. Wiley; Minnesota, MN, USA: 2018. p. 396.

411 Wiedmann M, Bruce JL, Keating C, Johnson AE, McDonough PL, Batt CA (1997) Ribotypes and virulence gene 412 polymorphisms suggest three distinct Listeria monocytogenes lineages with differences in pathogenic 413 potential. Infection and Immunity 65:2707-2716. https://doi.org/10.1128/iai.65.7.2707-2716.1997

414 Zhu Q, Gooneratne R, Hussain MA (2017) Listeria monocytogenes in fresh produce: outbreaks, prevalence and 415 contamination levels. Foods 6:21. https://doi.org/10.3390/foods6030021 
Figures

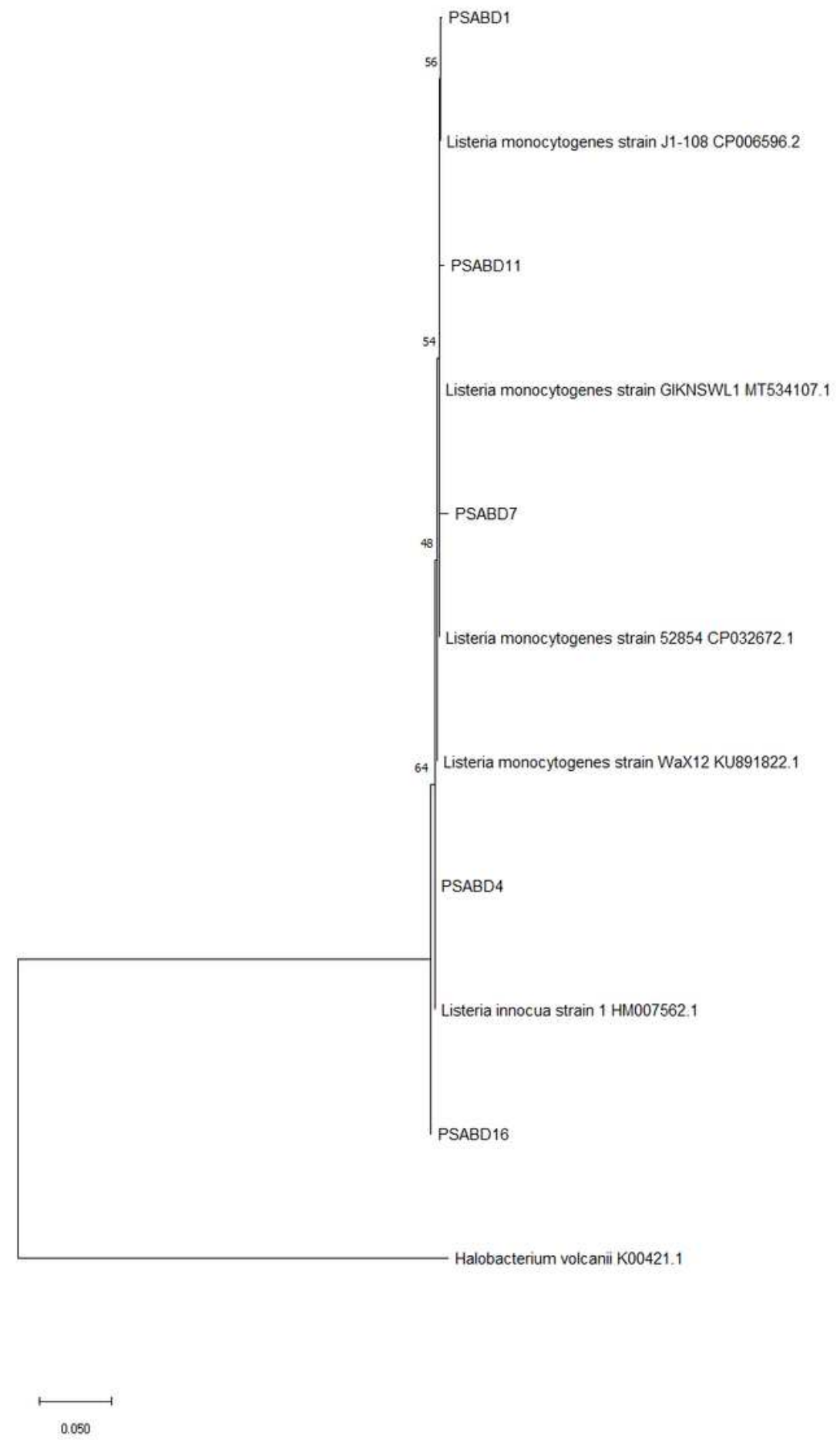

\section{Figure 1}

Phylogenetic analysis of partial 16S rRNA gene sequences and related species by neighbor-joining method 


\section{Figure 2}

PCR amplification of the genes $h / y A$ (picture A), actA (picture B) and $p / c B$ (Picture $C$ ). In all three gel pictures, lane $L$ represents $1 \mathrm{~kb}+\mathrm{DNA}$ ladder, and lanes 1 through 6 represent the negative control, the positive control (L. monocytogenes ATCC 19117) and the isolates PSABD1, PSABD7, PSABD11 and PSABD16 respectively.

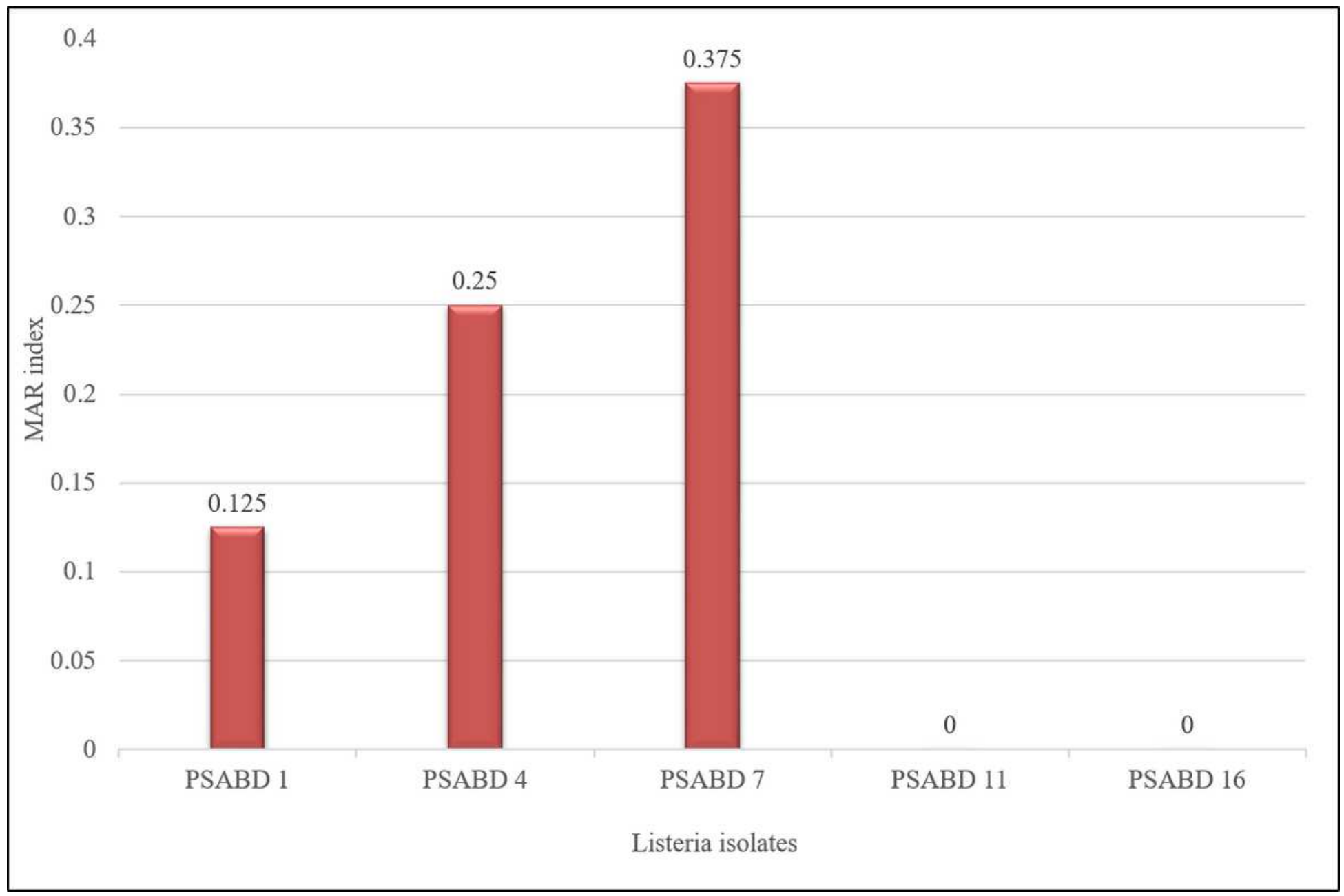

Figure 3

Multiple Antibiotic Resistance (MAR) index of the Listeria spp. isolate 